\title{
The state of voice user interfaces in Latin America
}

\author{
Adriana L. Iñiguez-Carrillo, Laura S. Gaytán-Lugo, Rocío Maciel-Arellano, \\ Miguel A. García-Ruiz, Daniel Aréchiga
}

Published: 30 November 2020

\begin{abstract}
This paper describes and analyzes the state of research in Voice User Interfaces (VUIs) in Latin America based on the review of scientific documents published in SCOPUS from 1999 to June 2020, through a bibliometric analysis. We analyzed 419 academic papers. Although a gradual increase is observed over the years, the number of published documents has increased considerably since 2014. Brazil (44\%) and Mexico (28\%) are the countries with more documents published. Co-authorship occurs between Latin American countries (Brazil, Argentina, Mexico, Ecuador, and Costa Rica). However, the mayor collaboration from Latin American countries occurs with the United States, France, Germany, Spain, Portugal, the United Kingdom, and Japan. The main researched topics are studies of automatic speech recognition, artificial intelligence, speech processing, and human-computer interaction, which have grown over the past few years. Natural language processing, conversational agents, user experience, and chatbots are keywords related to more recent studies. Our analysis reveals that the primary active research developed in the short-term future are personal assistants and assistive technology using voice user interfaces.
\end{abstract}

\section{Keywords:}

Voice user interfaces; Latin America; Automatic Speech Recognition; Personal Assistant.

\section{Introduction}

The use of voice interaction is every day (such as smart speakers, smart home appliances, voice assistants in cars, and robot assistants) [24]. The big tech companies (Alexa, Google, Apple, Facebook, IBM) have helped to popularize voice interactions by implementing speech interactions in their services. There are predictions that by 2021 , nearly $50 \%$ of new mobile apps use voice as a primary interface [31], and the speech technology market in Latin America has experienced exponential growth (figure 1),

Iniguez-Carrillo, A., Maciel-Arellano, R., Arechiga, D.

Universidad de Guadalajara

adriana.carrillo@cusur.udg.mx,rocio.maciel@cucea.udg.mx,

vdaniel@cusur.udg.mx

Gaytan-Lugo, L. S.

Universidad de Colima

laura@ucol.mx

Garcia-Ruiz, M. A

Algoma University

miguel.garcia@algomau.ca where it expects to be worth around 346 million US dollars by 2024. Latin America accounts for 8.53 percent of the global population [23]; taking into account the potential and prediction that has the use of VUIs, our main objective is to identify the research potential of VUIs and the Latin American scientific community's contribution to the development of VUIs identifying the following:

(Q1) The growth of VUI research in Latin America. Identify how the scientific community's interest has evolved over the years and compare its growth with the rest of the world.

(Q2) Main actors in the research. Recognize which countries, institutions, and researchers are conducting this research and where they publish

(Q3) Collaboration between actors. Establish collaboration between countries and researches. They relate to authors from their own country or those from abroad.

(Q4) Areas and context where VUIs are applied. Point out the topics of interest and the areas where the researchers work.

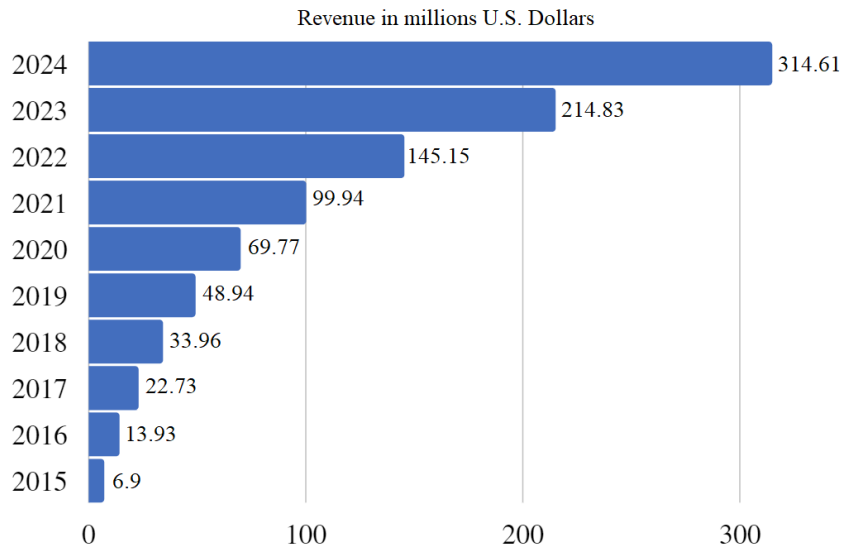

Figure 1. Size of the voice and speech recognition technology market in Latin America, from 2015 to 2024.

\section{Method}

A bibliometric analysis is performed using the Scopus, a bibliographic database of abstracts and citations of scientific journal articles. Scopus covers three types of sources: book series, journals, and trade journals. The search use terms related to VUIs (speech interface, conversational interface, automatic speech recognition, personal assistant, spoken language system, and dialog system) in English, Spanish, and Portuguese. It considers sentences that can refer to the descriptions (such as synonyms or 
abbreviations) searching these terms in the title, summary, and keywords, with a filter in the author's country of affiliation. A condition that determines the article's selection is that any document author is affiliated to a Latin American country. For identifying the research's growth over the years (Q1), no filter is applied in the year of publication. It is made a second search with the same terms, except the filter in the author's country of affiliation. We compare the differences between the documents published by year in the world versus Latin America with these two search results. With the first search results, a database is constructed considering the year in which the article is published, document title, author(s), source title, document type, affiliations, language, keywords, abstract, country, and context applied in voice interaction.

The search results are classified by the geographical distribution of publications, author name, author affiliation, and sources to identify who is doing the researches (Q2). The metadata is analyzed in VOSviewer software; this tool created maps based on a bibliographic database. With this, we can identify the collaboration between countries and researches (Q3). To classify the areas where VUIs are applied (Q4), the keywords are analyzed in VOSviewer ranking by occurrence and number of links between them, resulting in a cluster mapping. The 419 documents are analyzed for identifying the context where the VUIS are used. Most of the findings are presented in the form of frequency and percentage.

\section{Results}

A total of 419 academics papers are retrieved from 1999 to June of 2020. Four sources of documents are classified, conference proceedings $(52 \%)$, it refers to papers that are presented in conferences and are published. Journal (23\%) refers to a collection of articles that present the most recent research. Book series (24\%) is a serial publication with an overall series title, and books represent $1 \%$ of the total publications. It is essential to mention that the documents are in the following languages: English (90\%), Portuguese (6\%), and Spanish (4\%).

\subsection{Research Growth of VUIs}

The graph shows (figure 2) the increase in research related to speech technologies in Latin America. Although the growth is continuous, a substantial increasing tread in the number of published documents is observed since 2014. The year 2020 presents a decrease because it is the current year, and the annual count has not been completed. However, considering that the second part of the year is when more scientific articles are published, it is highly probable that the research's growth continues the trend of recent years.

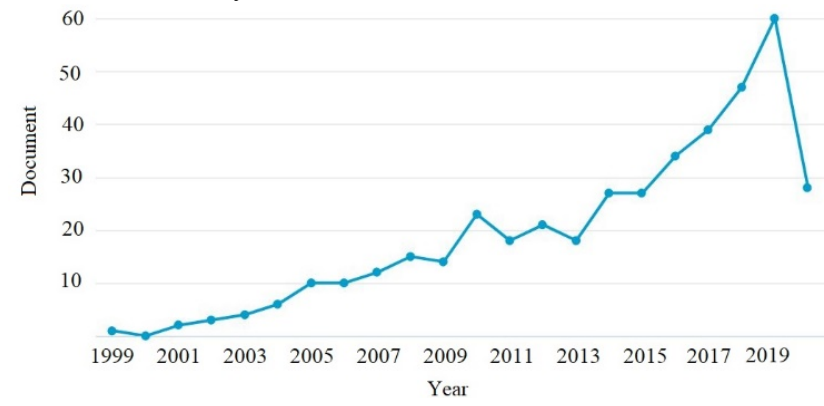

Figure 2. Documents published by year in Latin America.
Figure 3 shows a comparison between documents published worldwide (18,422 - blue line) and those published in Latin America (419 - red line). This region has a 3\% average of the publication worldwide and maintains a similar growth in percentage to the rest of the world. If Latin America is $8 \%$ of the world population and Spanish is the second-most spoken mother language, it could be inferred that the impact of research falls short in this area. Research on this topic is taking worldwide attention, and voice technology research is growing. It is necessary to pay attention to the advantages of developing and improving the current state to impact our society and help build conditions for more equitable development.

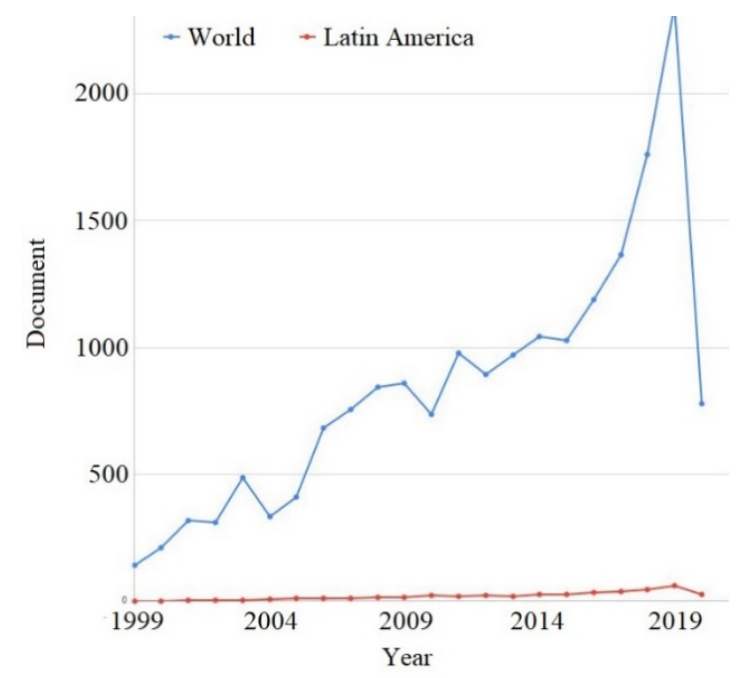

Figure 3. Comparison of documents published in the world versus Latin America.

\subsection{Main Characters in the VUIs Research}

To identify who is doing research related to VUIs, the search results are classified by the geographical distribution of publications, author name, author affiliation, and sources where more documents are published. Figure 4 shows the top countries contributed to the publication on voice user interfaces. Brazil ranked first with a total of $187(45 \%)$ documents followed by Mexico 113 (27\%), Argentina 37 (9\%), and Colombia 26 (6\%).

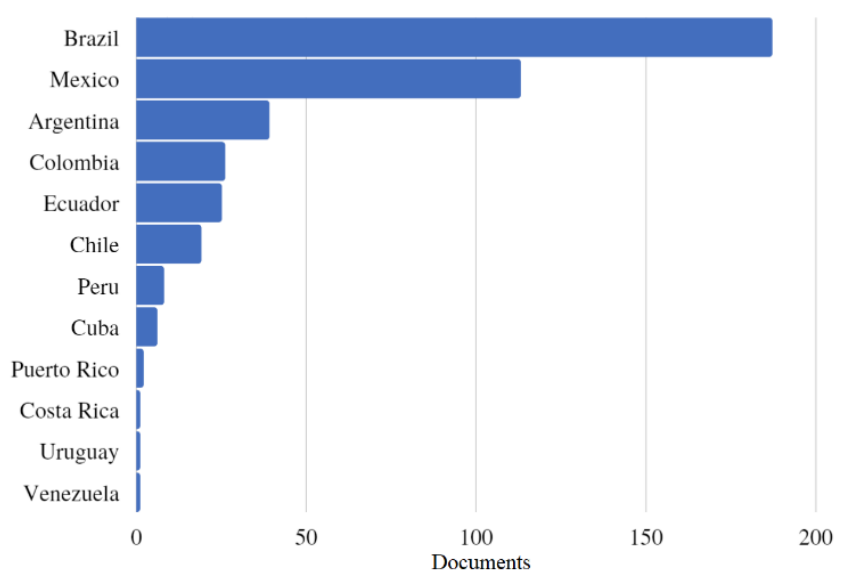

Figure 4. Documents by country territory. 
Regarding documents by affiliation, the University of Sao Paulo (USP), the National Polytechnic Institute of Mexico (IPN), and The Pontificia Catholic University of Paraná are the organizations that publish more academic papers about VUIs. Most of the documents are from universities $(84 \%)$, government research centers $(10 \%)$, and industry $(6 \%)$ have little participation, highlighting IBM in the industry (figure 5).

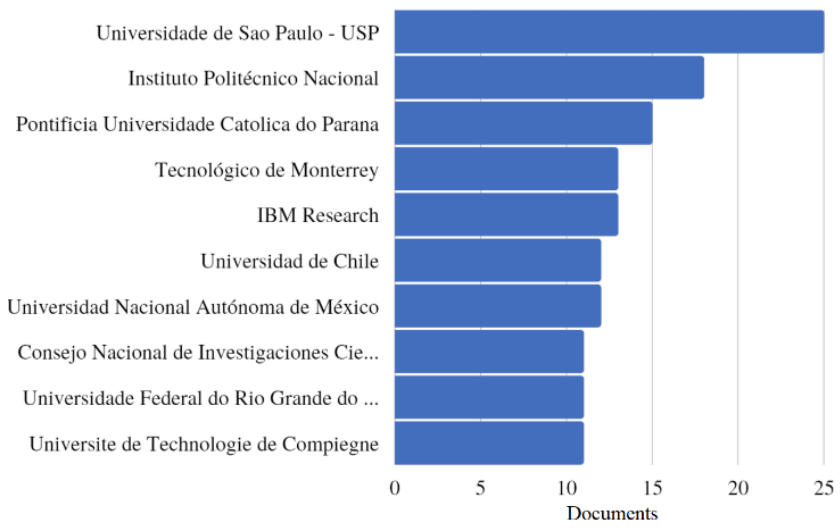

Figure 5. Documents by affiliation.

The source where more documents are published is in the "Lecture Notes In Computer Science Including Subseries Lecture Notes In Artificial Intelligence And Lecture Notes In Bioinformatics" and the "ACM International Conference Proceeding Series" like figure 6 shows.

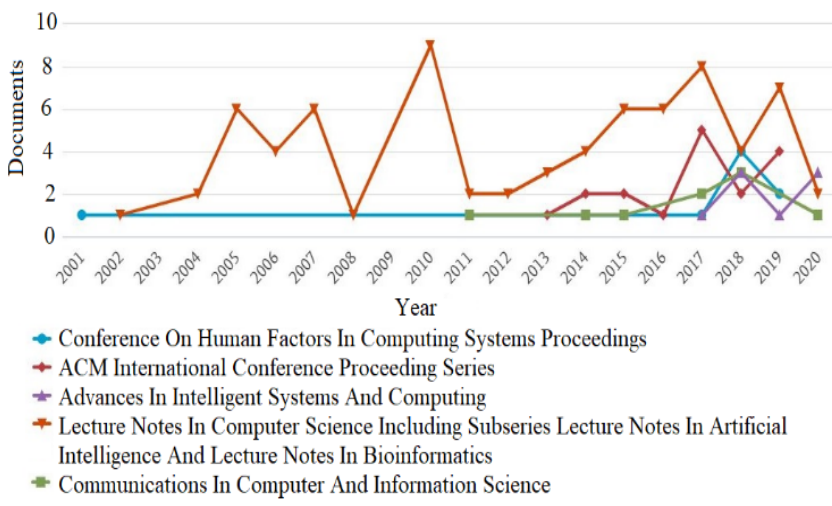

Figure 6. Documents per year by source.

Emerson Cabrera Paraiso of the Pontificia Universidade Catolica do Parana of Brazil is the author with more works (figure 7) about agents and machine learning. In recent years Heloísa Candello of IBM Research has already published work on Conversation Analysis, NLP, and speech processing.

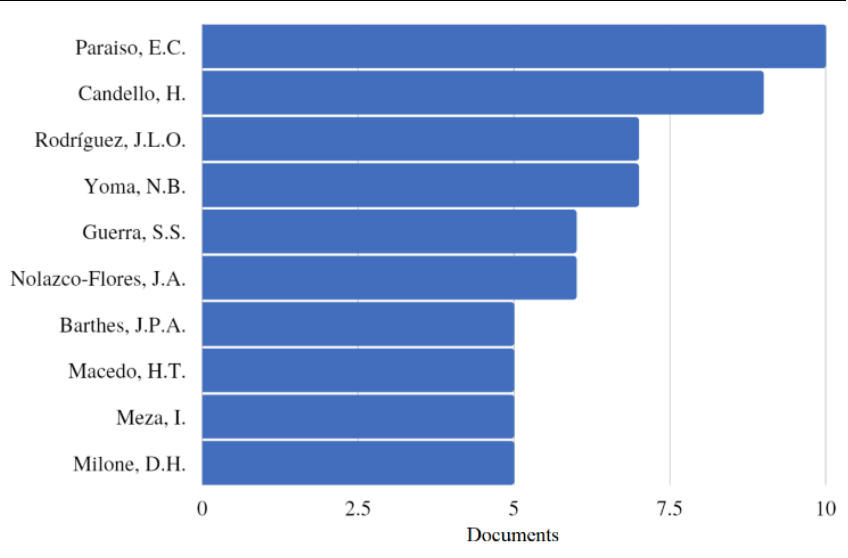

Figure 7. Documents by author.

\subsection{Latin American Research Collaboration}

Many search documents have authors belonging to different countries worldwide that share credits with Latin American authors. Brazil, Mexico, and Argentina are the countries with more co-authorship (table 1). The links column is the number of countries in which each country has a co-authorship, and the total link strength column is the co-authorships total number that the country has.

Table 1. Latin American countries co-authorship.

\begin{tabular}{|l|l|l|l|l|}
\hline Country & Links & Documents & Citations & $\begin{array}{l}\text { Total link } \\
\text { strength }\end{array}$ \\
\hline Brazil & 21 & 187 & 608 & 69 \\
\hline Mexico & 16 & 112 & 360 & 46 \\
\hline Argentina & 10 & 37 & 334 & 25 \\
\hline Chile & 8 & 18 & 245 & 16 \\
\hline Colombia & 6 & 26 & 105 & 10 \\
\hline Ecuador & 6 & 25 & 28 & 15 \\
\hline Peru & 5 & 8 & 12 & 6 \\
\hline Cuba & 3 & 6 & 19 & 6 \\
\hline $\begin{array}{l}\text { Puerto } \\
\text { Rico }\end{array}$ & 1 & 2 & 2 & 1 \\
\hline Uruguay & 0 & 1 & 0 & 0 \\
\hline Costa Rica & 1 & 1 & 0 & 1 \\
\hline Venezuela & 0 & 1 & 0 & 0 \\
\hline
\end{tabular}

Figure 8 shows the co-authorship relationships between these countries; the circumference size refers to the number of documents in which that country has participated. The thickness of the line connecting them depends on the number of documents that are carried out together. 


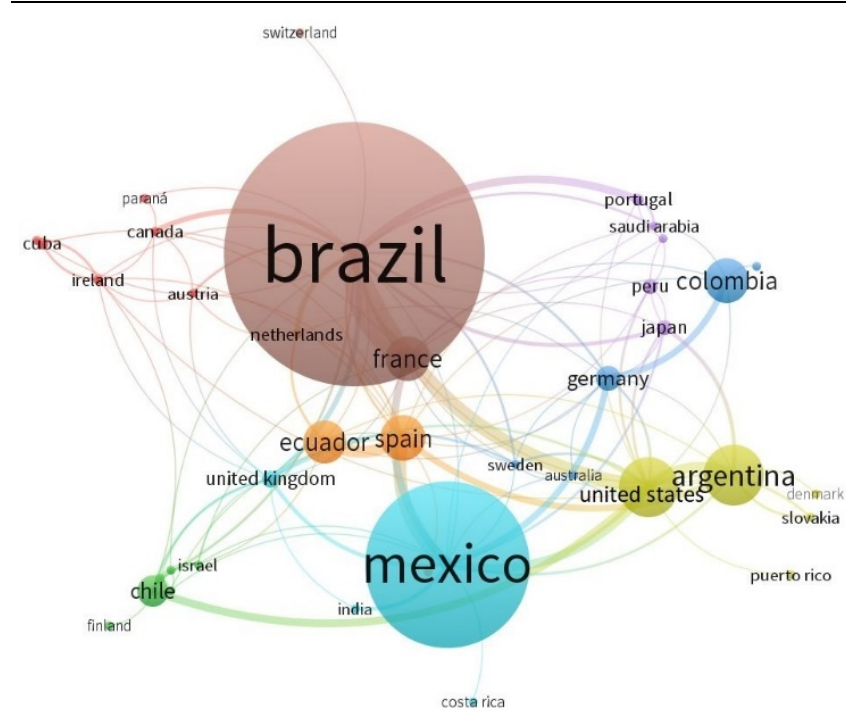

Figure 8. Countries co-authorship.

Brazil has the largest number of co-authorships with France (17), USA (11), and Portugal (6). Mexico with Spain (10), USA (7), and France (5). Argentina with USA (8), Spain (5), and Japan (3). Latin American countries have more co-authorship with countries worldwide, co-authorship between Latin American countries has occurred between Brazil, Mexico, Argentina, Ecuador, and Costa Rica. Ecuador and Peru have the most recent co-authorship documents (figure 9); the graphic color shows the documents' average year of publication. Peru with the United States and Spain, and Ecuador with Argentina, Germany, and Spain. It is possible to identify who leads the productivity in voice technology research and the opportunities for establishing collaboration between different countries in the same discipline.

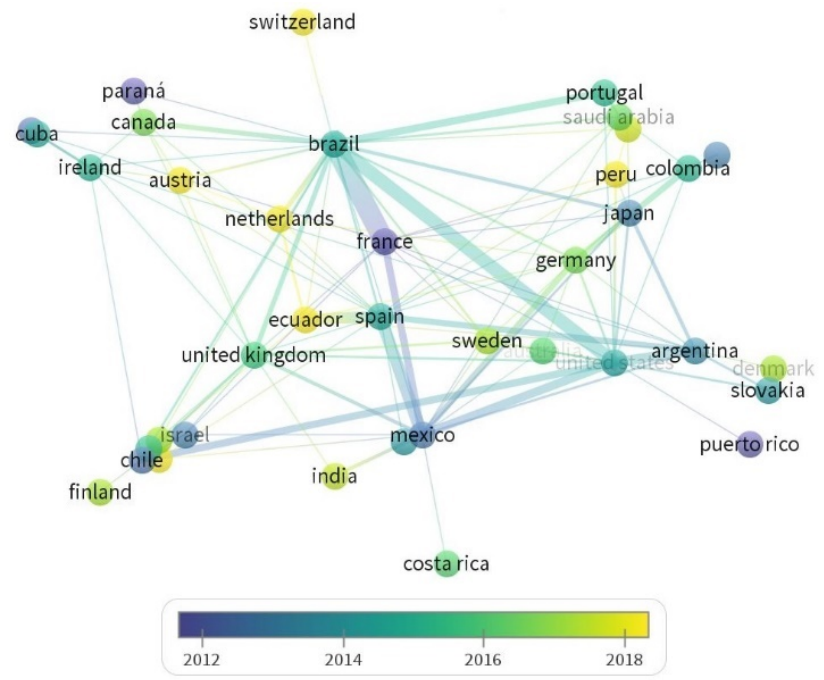

Figure 9. Latin American countries co-authorship.

This bibliometrics analysis reveals than 32 percent of the documents with authors affiliated to a Latin American country have collaborated with authors of other countries worldwide. Of these documents, only half have Latin American authors as the first author. Most collaborations occur between authors in the same country, where 47 percent of the documents are collaborations between authors in the same institution, and 20 percent are collaborations between authors of different institutions in the same country. Only one percent of the documents have co-authorship between Latin American countries, like Brazil and Mexico (figure $10)$.

Collaborations between colleagues in the same institution are common and natural; almost half of the documents have this characteristic. However, it is essential to increase collaboration between different institutions to explore different contexts, mainly focusing on increasing collaboration between Latin American countries.

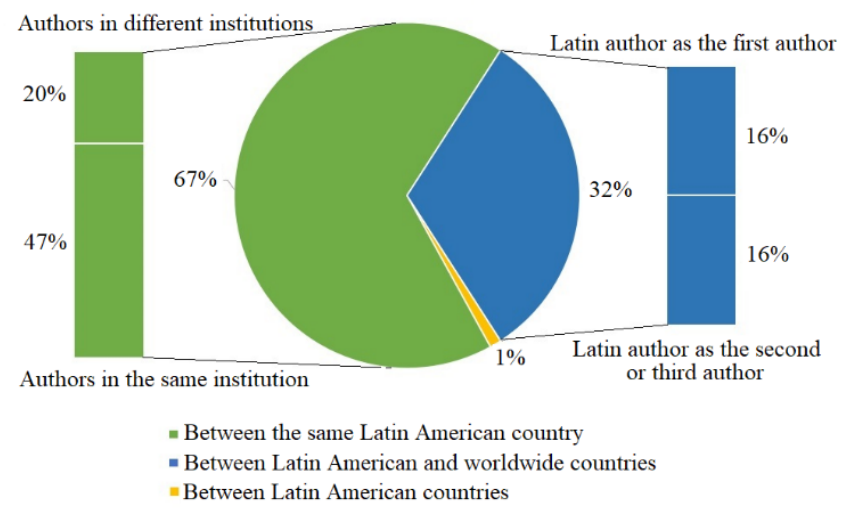

Figure 10. Latin America co-authorship.

Regarding the authors with an affiliation in Latin America, Heloisa Candelo and Claudio Pinhanez from Brazil IBM Research Lab are the authors with more co-authorship. In figure 11, we can identify the interactions between the authors. The circumference size is related to the number of documents that the author has published, and the thicker link means that there is more collaboration between these two authors.

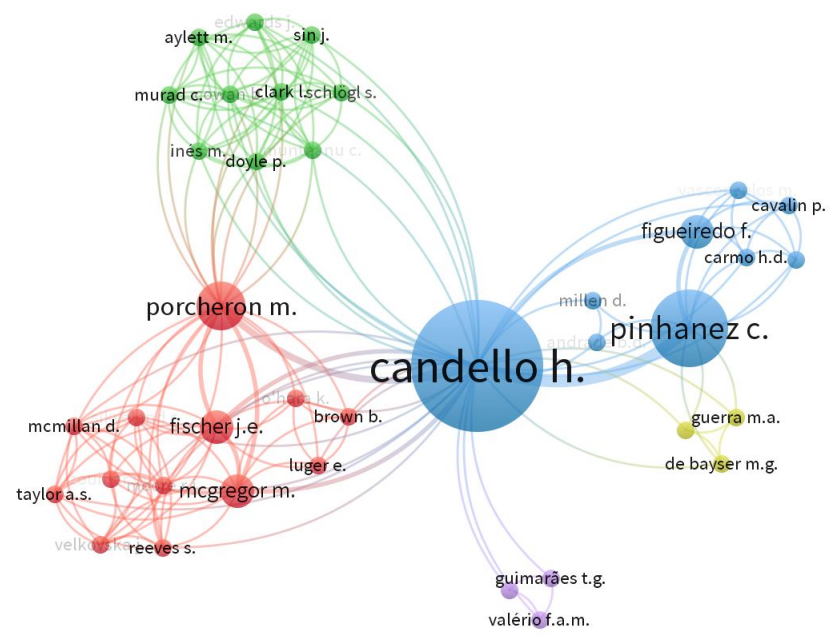

Figure 11. Documents by authors co-authorship.

The collaboration networks that authors have formed are visible, with very well determined groups and the authors who have collaborated with different groups of researchers. Candello's extensive collaboration with different groups of researchers is very notable. The average co-authorship between these authors are 
between 2017 and 2020; the co-authorship is increased in these last years. It should be noted that most of the authors with whom collaboration is made are from Brazil.

Latin American authors have performed an international collaboration from the first researches of this study. Co-authorship networks between the same department or laboratory have advantages like the same research lines, shared resources, and similar objectives. However, co-authorship networks allow increasing the scope, visibility, and perspectives that can enrich the research.

\subsection{Areas where VUIs are Researched}

The selected works' keywords are analyzed to identify the areas researched; then, each document is analyzed to identify the context where VUIs are applied.

\subsubsection{Keywords}

Using VOSviewer software is created a map based on bibliographic data (figure 12). The type of analysis is cooccurrence, where the relatedness of items is determined based on their number of documents in which they occur together and the counting method is full counting, the unit of analysis is all keywords, considering 13 like the minimum number of occurrences of a keyword, of the 3219 keywords, 38 meet the threshold. Based on common keywords that each work has, four general groups are identified, researches based on the study of the interaction between humans and speech systems (red section, cluster 1), development of speech technology (green section, cluster 2), speech processing (blue section, cluster 3), and artificial intelligence (yellow section, cluster 4). The circumference size is proportional to the number of academic papers presented and the relationship between keywords is observed by the distance.

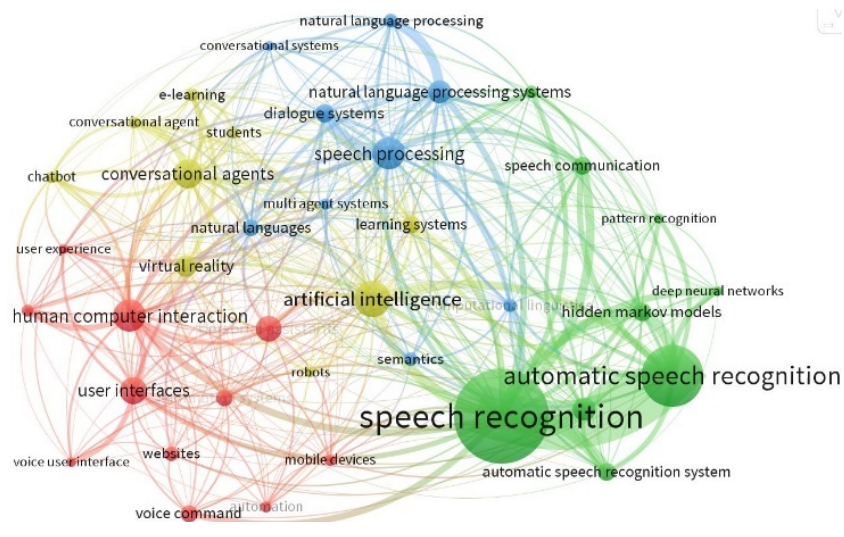

Figure 12. Documents by keyword.

Table 2 shows these keywords, the cluster in which each keyword is classified depending on with which other keywords have more links, the total strength of the co-occurrence link with other keywords is calculated, as well as the number of keywords with which it is related (links) and the total link strength than is the number of links it has with all the other keywords with which it is related. Human-computer interaction, automatic speech recognition, speech processing, artificial intelligence, and conversational agents are the keywords with the highest occurrence, with which we can see the trend areas in voice technology research.
Table 2. Keyword.

\begin{tabular}{|c|c|c|c|c|}
\hline Keyword & Cluster & Occurrence & Links & $\begin{array}{c}\text { Total } \\
\text { link } \\
\text { strength }\end{array}$ \\
\hline Automation & 1 & 14 & 16 & 29 \\
\hline $\begin{array}{l}\text { Human } \\
\text { computer } \\
\text { interaction }\end{array}$ & 1 & 46 & 34 & 130 \\
\hline $\begin{array}{l}\text { Human } \\
\text { engineering }\end{array}$ & 1 & 15 & 19 & 48 \\
\hline $\begin{array}{l}\text { Information } \\
\text { systems }\end{array}$ & 1 & 22 & 25 & 46 \\
\hline Mobile devices & 1 & 14 & 18 & 35 \\
\hline $\begin{array}{l}\text { Personal } \\
\text { assistants }\end{array}$ & 1 & 36 & 27 & 65 \\
\hline User experience & 1 & 13 & 17 & 46 \\
\hline User interfaces & 1 & 38 & 29 & 93 \\
\hline Voice command & 1 & 23 & 15 & 39 \\
\hline $\begin{array}{l}\text { Voice user } \\
\text { interface }\end{array}$ & 1 & 13 & 14 & 30 \\
\hline Websites & 1 & 19 & 17 & 32 \\
\hline $\begin{array}{l}\text { Automatic } \\
\text { speech } \\
\text { recognition }\end{array}$ & 2 & 94 & 26 & 230 \\
\hline $\begin{array}{l}\text { Automatic } \\
\text { speech } \\
\text { recognition } \\
\text { system }\end{array}$ & 2 & 24 & 19 & 64 \\
\hline $\begin{array}{l}\text { Deep neural } \\
\text { networks }\end{array}$ & 2 & 13 & 15 & 43 \\
\hline $\begin{array}{l}\text { Hidden markov } \\
\text { models }\end{array}$ & 2 & 25 & 19 & 74 \\
\hline Linguistics & 2 & 16 & 23 & 58 \\
\hline $\begin{array}{l}\text { Pattern } \\
\text { recognition }\end{array}$ & 2 & 13 & 18 & 38 \\
\hline Speech & 2 & 32 & 22 & 102 \\
\hline $\begin{array}{l}\text { Speech } \\
\text { communication }\end{array}$ & 2 & 24 & 22 & 77 \\
\hline $\begin{array}{l}\text { Speech } \\
\text { recognition }\end{array}$ & 2 & 151 & 34 & 340 \\
\hline $\begin{array}{l}\text { Computational } \\
\text { linguistics }\end{array}$ & 3 & 17 & 22 & 66 \\
\hline $\begin{array}{l}\text { Conversational } \\
\text { systems }\end{array}$ & 3 & 13 & 21 & 39 \\
\hline $\begin{array}{l}\text { Dialogue } \\
\text { systems }\end{array}$ & 3 & 25 & 23 & 86 \\
\hline $\begin{array}{l}\text { Multi agent } \\
\text { systems }\end{array}$ & 3 & 14 & 15 & 25 \\
\hline
\end{tabular}




\begin{tabular}{|l|c|c|c|c|}
\hline Keyword & Cluster & Occurrence & Links & $\begin{array}{c}\text { Total } \\
\text { link } \\
\text { strength }\end{array}$ \\
\hline NLP & 3 & 18 & 22 & 63 \\
\hline NLP systems & 3 & 32 & 27 & 103 \\
\hline $\begin{array}{l}\text { Natural } \\
\text { languages }\end{array}$ & 3 & 22 & 28 & 78 \\
\hline Semantics & 3 & 18 & 21 & 45 \\
\hline $\begin{array}{l}\text { Speech } \\
\text { processing }\end{array}$ & 3 & 46 & 30 & 132 \\
\hline $\begin{array}{l}\text { Artificial } \\
\text { intelligence }\end{array}$ & 4 & 52 & 35 & 139 \\
\hline Chatbot & 4 & 15 & 16 & 44 \\
\hline $\begin{array}{l}\text { Conversational } \\
\text { agent }\end{array}$ & 4 & 15 & 23 & 56 \\
\hline $\begin{array}{l}\text { Conversational } \\
\text { agents }\end{array}$ & 4 & 41 & 32 & 114 \\
\hline E-learning & 4 & 17 & 22 & 48 \\
\hline $\begin{array}{l}\text { Learning } \\
\text { systems }\end{array}$ & 4 & 24 & 26 & 73 \\
\hline Robots & 4 & 14 & 21 & 38 \\
\hline Students & 30 & 24 & 59 \\
\hline Virtual reality & 4 & 17 & 29 \\
\hline
\end{tabular}

Figure 13 shows the human-computer interaction keyword and the other keywords with which is related. It can be seen how human-computer interaction is related to various areas of voice technology research, such as conversational agents, chatbot, dialog systems, speech processing, speech recognition.

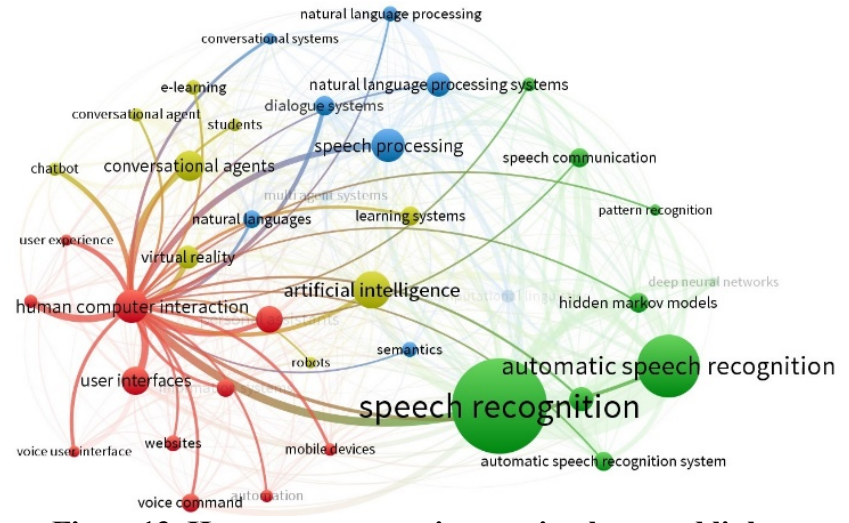

Figure13. Human-computer interaction keyword links.

Voice user interface keyword is related to 14 keywords (figure 14), like conversational agents, speech recognition, user interfaces, user experience, human-computer interactions, voice command, to name a few.

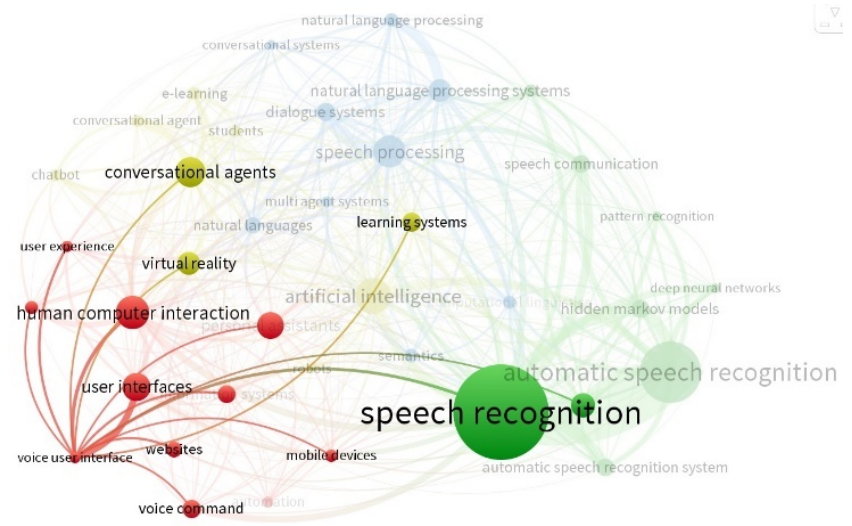

Figure 14. Voice user interaction keyword links.

Figure 15 shows the average publication year of the keywords represented by colors. Natural language processing, conversational agents, user experience, and chatbots are keywords with more recent studies.

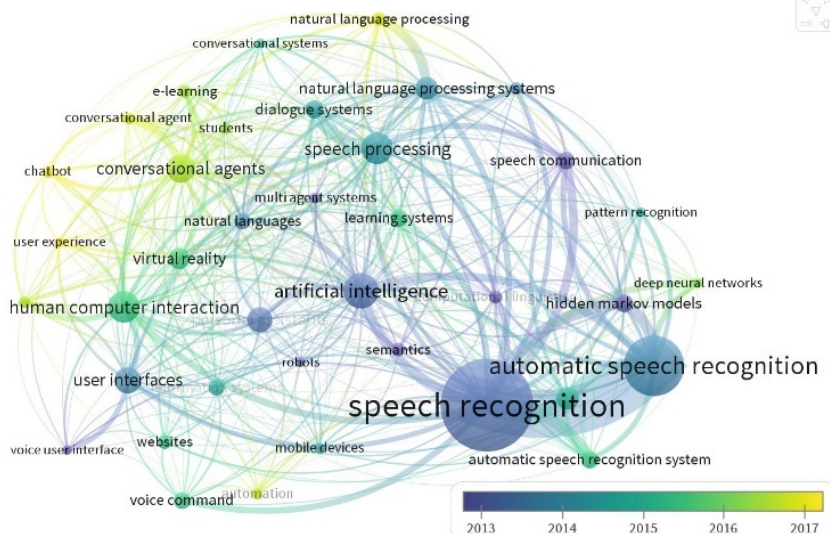

Figure 15. Documents by keyword and average year of publication.

\subsubsection{Context}

Speech technology (34\%), personal assistants (13\%), assistive technology $(10 \%)$, and health $(8 \%)$ are the significant areas where voice user interfaces are studied (Table 3). Concerning speech technology, some of the topics identified are analysis dialog and prosody, speech recognition, neural network, the use of Markov models, and noise analysis [1][4][28][26].

Table 3. Context of use.

\begin{tabular}{|l|l|}
\hline Context area & Percent of documents \\
\hline Assistive technology & 10 \\
\hline Customer Service & 1 \\
\hline Education & 6 \\
\hline Entertainment & 3 \\
\hline Health & 8 \\
\hline Information visualization & 1 \\
\hline Internet of things & 3 \\
\hline
\end{tabular}




\begin{tabular}{|l|l|}
\hline Context area & Percent of documents \\
\hline Language & 4 \\
\hline Management & 0.5 \\
\hline Personal assistant & 13 \\
\hline Robotics & 5 \\
\hline Searches \& queries & 4 \\
\hline Smart building & 3 \\
\hline Speech design & 1 \\
\hline Speech technology & 34 \\
\hline Telephone operator & 0.5 \\
\hline Virtual environment & 3 \\
\hline
\end{tabular}

The VUIs research using a personal assistant focus on the improvement of their use, and how to use it in collaborative environments and for a specific purpose like a financial adviser, government services, operators, receptionist, travel assistant, for sales, web services discovery, just to mention a few [25][22][27]. There are assistive technology applications for sign language, visual impairments, deaf or hard of hearing, disorder speech, motor impairment, and limited physical mobility [6][9]. Customer services like call centers and virtual agents are used [5]. In the context of education, VUIs are used for learning different subjects like electronics, electricity, programming, and science [20][7]. Speech is used too into the entertainment world by example, in an art exhibit using a conversational interface, in games and news online and some case studies based on web content [8][13].

For therapy generation for Alzheimer's, in speech rehabilitation, for Parkinson's patients, motor rehabilitation, postCVA therapist, virtual trainer, dementia, clinical psychology, and psychiatry [16]. Exist apps to prevent cyber-pedophilia and for the prevention and detection of suicidal behavior [15]. As a support in handling medical equipment, in the transcription of radiology reports, in intraoperative endoscopy positioning, for a triage system, in biological information retrieval, and as a personal assistant in health environments and for identifying rare diseases [12]. For controlling industrial and building plant and device with voice, in ubiquitous applications [11]. In the area of robotics there are studies about the use of speech with hand tracking application, receptionist robots, robot suitability, social robots, perform a task with voice commands, tour-guide robot, training of a dialogue system, framework for collaborative interaction, controlling navigation, conversational service robots, semantic reasoning in service robots, intelligence implementation, context analysis and middleware for robotic applications [2][3][29].

Voice interaction is an integral part of the use of a smart environment. Many studies are for control in multimodal interactions, for protocols, offline system, and production system management [30]. The design plays a vital role in having better voice interactions; some documents analyze design issues, frameworks for voice, the life cycle of designing, usability evaluators, and heuristics [17]. There are voice applications in virtual environments for collaborative learning, games, street view, government services, and simulators [18]. There are several studies on the improvement of queries and searches using voice [10]. There are studies in the use of languages like Portuguese, Nahuatl,
Mixtec, Quechua, Spanish, Huichol, Mixtec, and Zapotec [19][14][21].

Over the years, a small decrease in speech technology studies and an increase in studies of the use of assistive technology and personal assistants can be observed (Figure 16).

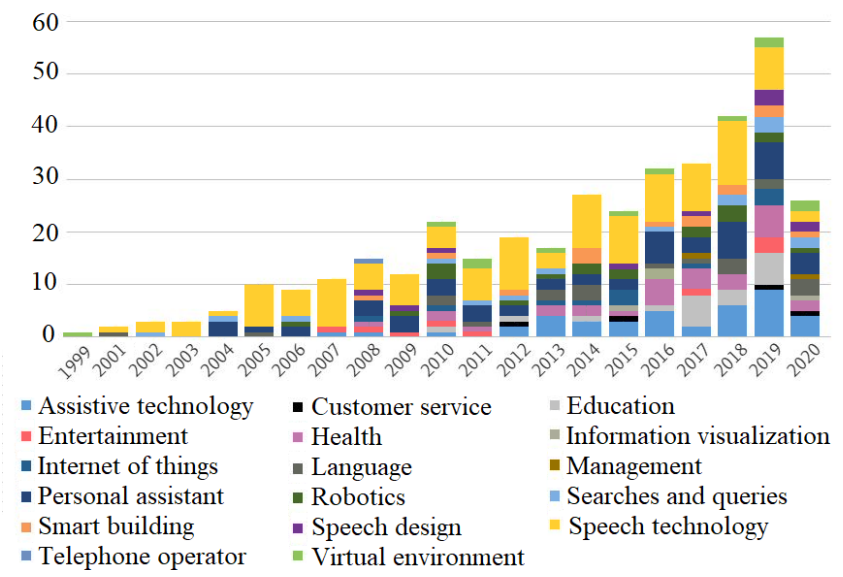

Figure 16. Documents by the context of use over the years.

Brazil has more studies on assistive technology, health, speech technology, and personal assistants. Argentina in education, personal assistants, and speech technology. Chile in speech technology. Mexico in assistive technology, health, languages, and speech technology.

\section{Conclusion}

The result of thirty years of scientific research of voice user interfaces in Latin America is applied to various subject areas (such as human-computer interaction, automatic speech recognition, speech processing, artificial intelligence, conversational agents). Since 2014, the production of scientific papers on voice user interfaces has grown. At the moment, 419 academic papers on voice user interfaces are published; they are $3 \%$ of the worldwide publications. It is crucial to increase the research in voice user interfaces due to the predictions that this kind of interface will be used as a primary interface during subsequent years.

The main objective of this work is to identify the research potential of VUIs. It can be observed that VUI researches have an international interest, and they are increasing in recent years. It is important to note the need to increase research in the Spanish language since it is the second mother tongue by the number of speakers. Moreover, it can have a favorable impact on a better understanding of users and improve this technology's use to develop the region better.

Brazil, Mexico, Argentina, and Colombia have the most scientific works published, and the most prolific authors are from Brazil and Mexico. Co-authorship occurs between Latin American countries (Brazil, Argentina, Mexico, Ecuador, and Costa Rica). However, mayor collaboration occurs with countries outside the region such as the United States, France, Germany, Spain, Portugal, the United Kingdom, and Japan.

The main researched topics are studies of automatic speech recognition and artificial intelligence. However, in recent years, human-computer interaction, speech processing, and conversational agents have grown. A particularly important research topic that Latin American researchers have contributed is to the development of VUI and interactions based on native tongues 
(Spanish and Portuguese), and native languages (such as Nahuatl, Mixtec, Quechua, Huichol, Zapotec). Natural language processing, conversational agents, user experience, and chatbots are keywords with more recent studies. The undertaken analysis reveals that active research areas that will be developed in the short-term future: personal assistant and assistive technology using voice user interfaces.

\section{References}

[1] M Alexandrov, E S Arnal, and P Rosso. 2005. Cluster analysis of railway directory inquire dialogs. 8th International Conference on Text, Speech and Dialogue, TSD 20053658 LNAI, 385-392. Retrieved from https://www.scopus.com/inward/record.uri?eid=2-s2.0$33646037356 \&$ partnerID $=40 \& \mathrm{md} 5=2$ f793edf95af5743d780 ace8f5cdd03e

[2] H Avilés, M Alvarado-González, E Venegas, C Rascón, I V Meza, and L Pineda. 2010. Development of a tour-guide robot using dialogue models and a cognitive architecture. 12th Ibero-American Conference on Advances in Artificial Intelligence, AI 20106433 LNAI, 512-521. DOI:https://doi.org/10.1007/978-3-642-16952-6 52

[3] H Avilés, I Meza, W Aguilar, and L Pineda. 2010. Integrating pointing gestures into a Spanish-spoken dialog system for conversational service robots. In 2nd International Conference on Agents and Artificial Intelligence, ICAART 2010, Department of Computer Science, Institute de Investigaciones en Matemáticas Aplicadas y en Sistemas, Universidad Nacional Autónoma de México, Circuito Escolar, D.F. 04510, Mexico, 585-588. Retrieved from https://www.scopus.com/inward/record.uri?eid=2-s2.0$77956278725 \&$ partnerID $=40 \& \mathrm{md} 5=35 \mathrm{e} 0 \mathrm{af} 91 \mathrm{~b} 26124 \mathrm{aada} 8 \mathrm{~d}$ $8 \mathrm{~d} 0500916 \mathrm{~d} 62$

[4] G C Batista, W L S Silva, and A G Menezes. 2017. Automatic speech recognition using Support Vector Machine and Particle Swarm Optimization. In 2016 IEEE Symposium Series on Computational Intelligence, SSCI 2016, Institute of Electrical and Electronics Engineers Inc., Federal Institute of Maranhao, Electrical Engineering, Sao Luis, Maranhao, Brazil. DOI:https://doi.org/10.1109/SSCI.2016.7850125

[5] A Bender, F G Calabria, N Mazza, and S Nicolet. 2015. Customer service virtual agents for Spanish speaking users. In 6th International Multi-Conference on Complexity, Informatics and Cybernetics, IMCIC 2015, Jointly with the 6th International Conference on Society and Information Technologies, ICSIT 2015, International Institute of Informatics and Systemics, IIIS, Information Systems Engineering, Universidad Del Salvador, Buenos Aires, Argentina, 155-159. Retrieved from https://www.scopus.com/inward/record.uri?eid=2-s2.085033553751\&partnerID $=40 \&$ md5 $=\mathrm{dbfd} 7115870847 \mathrm{e} 3 \mathrm{c} 613$ $76 \mathrm{e} 8 \mathrm{c} 4255 \mathrm{fOf}$

[6] S.-O. Caballero-Morales and F Trujillo-Romero. 2013. 3D modeling of the mexican sign language for a speech-to-sign language system. Comput. y Sist. 17, 4 (2013), 593-608. DOI:https://doi.org/10.13053/CyS-17-4-2013-011

[7] D Caballero, R Araya, H Kronholm, J Viiri, A Mansikkaniemi, S Lehesvuori, T Virtanen, and M Kurimo. 2017. ASR in classroom today: Automatic visualization of conceptual network in science classrooms. 12th European Conference on Technology Enhanced Learning, EC-TEL 2017 10474 LNCS, 541-544. DOI:https://doi.org/10.1007/978-3319-66610-5 58
[8] H Candello, C Pinhanez, M Pichiliani, P Cavalin, F Figueiredo, M Vasconcelos, and H D Carmo. 2019. The effect of audiences on the user experience with conversational interfaces in physical spaces. In 2019 CHI Conference on Human Factors in Computing Systems, CHI 2019, Association for Computing Machinery, IBM Research, United States. DOI:https://doi.org/10.1145/3290605.3300320

[9] M A Contreras-Castãeda, J A Holgado-Terriza, G PombozaJunez, P Paderewski-Rodríguez, and F L Gutiérrez-Vela. 2019. Smart home: Multimodal interaction for control of home devices. In 22nd International Conference on HumanComputer Interaction, INTERACCION 2019, Association for Computing Machinery, Software Engineering Department, Universidad de Granada, Granada, Spain. DOI:https://doi.org/10.1145/3335595.3335636

[10] H Hromic and J Atkinson. 2012. Stochastic web-based natural language dialog planning for web information filtering. Expert Syst. Appl. $\quad 39, \quad 10 \quad$ (2012), 9420-9426. DOI:https://doi.org/10.1016/j.eswa.2012.02.122

[11] A H Kronbauer and V F Costa. 2015. A New approach to the interpretation of voice commands. In 21st Brazilian Symposium on Multimedia and the Web, WebMedia 2015, Association for Computing Machinery, Inc, PPGCOMP UNIFACS, Alameda das Espatódias, 915, Salvador - BA, Brazil, $217-224$ DOI:https://doi.org/10.1145/2820426.2820431

[12] A O C Lambert, C H T Montañez, M B Martinez, and M Funes-Gallanzi. 2017. A conversational agent for use in the identification of rare diseases. International Summit on Applications for Future Internet, AFI 2016179 LNICST, 128139. DOI:https://doi.org/10.1007/978-3-319-49622-1_15

[13] A M A Maciel and E C B Carvalho. 2007. Voice user interface using voicexml: Environment, architecture and dialogs initiative. In SIGMAP 2007 - International Conference on Signal Processing and Multimedia Applications, Center of Informatics, Federal University of Pernambuco, Recife, Brazil, 380-384. Retrieved from https://www.scopus.com/inward/record.uri?eid=2-s2.070349451855\&partnerID $=40 \&$ md5 $=39 \mathrm{~d} 968 \mathrm{~d} 653840295172$ 2bd9b7f8c 7396

[14] M Mager, D Carrillo, and I Meza. 2018. Probabilistic FiniteState morphological segmenter for Wixarika (huichol) language1. J. Intell. Fuzzy Syst. 34, 5 (2018), 3081-3087. DOI:https://doi.org/10.3233/JIFS-169492

[15] J Martínez-Miranda, A Martínez, R Ramos, H Aguilar, L Jiménez, H Arias, G Rosales, and E Valencia. 2019. Assessment of users' acceptability of a mobile-based embodied conversational agent for the prevention and detection of suicidal behaviour. J. Med. Syst. 43, 8 (2019). DOI:https://doi.org/10.1007/s10916-019-1387-1

[16] M L Morales-Rodríguez, J J González B., R Florencia Juárez, H J Fraire Huacuja, and J A Martínez Flores. 2010. Emotional conversational agents in clinical psychology and psychiatry. 9th Mexican International Conference on Artificial Intelligence, MICAI 20106437 LNAI, 458-466. DOI:https://doi.org/10.1007/978-3-642-16761-4_40

[17] A T Neto, T J Bittar, R P M Fortes, and K Felizardo. 2009. Developing and evaluating web multimodal interfaces - A case study with usability principles. In 24th Annual ACM Symposium on Applied Computing, SAC 2009, USP ICMC, P.O. Box 668, São Carlos, SP, Brazil, 116-120. DOI:https://doi.org/10.1145/1529282.1529306

[18] A V Netto. 2015. Application of Interactive Technology for 
Training in the Security Area . In 17th Symposium on Virtual and Augmented Reality, SVR 2015, Institute of Electrical and Electronics Engineers Inc., Diretoria de Inovacąõ e Novos Negócios, Cientistas Desenvolvimento Tecnológico Ltd, Saõ Carlos, SP, Brazil, $127-132$. DOI:https://doi.org/10.1109/SVR.2015.25

[19] J A Nolazco-Flores, L R Salgado-Garza, and M Peña-Díaz. 2005. Speaker dependent ASRs for huastec and westernhuastec náhuatl languages. In Second Iberian Conference on Pattern Recognition and Image Analysis, IbPRIA 2005, Departamento de Ciencias Computacionales, ITESM, Campus Monterrey, Av. Eugenio Garza Sada 2501 Sur, N.L., México, C.P. 64849, Mexico, 595-602. Retrieved from https://www.scopus.com/inward/record.uri?eid=2-s2.0$25144445744 \&$ partnerID $=40 \& \mathrm{md} 5=\mathrm{a} 79 \mathrm{fe} 9 \mathrm{f} 15 \mathrm{fb} 9 \mathrm{f} 9 \mathrm{a} 8 \mathrm{f} 7 \mathrm{e} 88 \mathrm{f}$ $24 \mathrm{~b} 29 \mathrm{a} 5 \mathrm{c} 1 \mathrm{c}$

[20] J M Ocaña Ch., E Morales-Urrutia, D Pérez-Marín, and S Tamayo. 2019. Pedagogic conversational agent dialogue management to learn how to program . RISTI - Rev. Iber. Sist. e Tecnol. Inf. 2019, 19 (2019), 239-251. Retrieved from https://www.scopus.com/inward/record.uri?eid=2-s2.085069195488\&partnerID $=40 \& \mathrm{md} 5=\mathrm{e} 93161 \mathrm{de} 8 \mathrm{dd} 28 \mathrm{fcdb} 1 \mathrm{ef}$ ec8f99263199

[21] G Oliva-Juarez, F Martinez-Licona, A Martinez-Licona, and J Goddard-Close. 2014. Identification of vowel sounds of the Choapan variant of Zapotec language. 13th Mexican International Conference on Artificial Intelligence, MICAI 2014 8857, 252-262. Retrieved from https://www.scopus.com/inward/record.uri?eid=2-s2.084914104333\&partnerID $=40 \&$ md5 $=3$ b1721206b5d5e9deb9 8 b523bd40a779

[22] E C Paraiso and J.-P.A. Barthès. 2005. A voice-enabled assistant in a multi-agent system for e-government services. Advanced Distributed Systems - 5th International School and Symposium, ISSADS 2005, Revised Selected Papers 3563 LNCS, 495-503. Retrieved from https://www.scopus.com/inward/record.uri?eid=2-s2.0$33646020421 \&$ partnerID $=40 \&$ md5 $=34654$ ca4deaa 1429 eb4 2 bb5e9df33afc

[23] H Plecher. 2019. Latin America - Statistics \& Facts. Retrieved October 22, 2019 from https://www.statista.com/topics/3287/latin-america/

[24] Martin Porcheron, Joel E Fischer, Stuart Reeves, and Sarah Sharples. 2018. Voice Interfaces in Everyday Life. (2018).

[25] M P Ramos, C A Tacla, G Y Sato, E C Paraiso, and J.-P.A.
Barthès. 2010. Dialog construction in a collaborative project management environment. In Proceedings of the 2010 14th International Conference on Computer Supported Cooperative Work in Design, CSCWD 2010, IEEE Computer Society, TECPAR - Paraná, Institute of Technology, Artificial Intelligence Division, Curitiba, Brazil, 269-273. DOI:https://doi.org/10.1109/CSCWD.2010.5471963

[26] D Ribas, E Vincent, and J R Calvo. 2015. Uncertainty propagation for noise robust speaker recognition: The case of NIST-SRE. In 16th Annual Conference of the International Speech Communication Association, INTERSPEECH 2015, International Speech and Communication Association, Advanced Technologies Application Center (CENATAV), Habana, Cuba, 3536-3540. Retrieved from https://www.scopus.com/inward/record.uri?eid=2-s2.084959111417\&partnerID=40\&md5=3aef9ac16e5e99aa8f799 8a08f870417

[27] F Schlesinger, E Ferretti, M Errecalde, and G Aguirre. 2010. An argumentation-based BDI personal assistant. 23rd International Conference on Industrial Engineering and Other Applications of Applied Intelligence Systems, IEA/AIE 20106096 LNAI, 701-710. DOI:https://doi.org/10.1007/9783-642-13022-9 70

[28] J Silva and S Narayanan. 2008. Upper bound Kullback-Leibler divergence for transient hidden Markov models. IEEE Trans. Signal Process. 56, 9 (2008), 4176-4188. DOI:https://doi.org/10.1109/TSP.2008.924137

[29] M V D Veloso, J T C Filho, and G A Barreto. 2017. SOM4R: a Middleware for Robotic Applications Based on the Resource-Oriented Architecture. J. Intell. Robot. Syst. Theory Appl. 87, 3-4 (2017), 487-506. DOI:https://doi.org/10.1007/s10846-017-0504-y

[30] J P Victor Alfonso, P Jhonatan, and G A Luis Felipe. 2014. Design of an automatic voice controlled system and remote control. In 2014 3rd International Congress of Engineering Mechatronics and Automation, CIIMA 2014, Institute of Electrical and Electronics Engineers Inc., Mechatronics Engineering Program, Department of Physics, University of Caldas, Manizales, Colombia. DOI:https://doi.org/10.1109/CIIMA.2014.6983461

[31] Ricardo Villate. 2017. IDC FutureScape: Worldwide IT Industry 2018 Predictions- Latin America Implications. 32. Retrieved October 26, 2019 from http://www.idclatin.com/microsites/FutureScapes2018/LA_F uturescape_2018_Final_SP.pdf

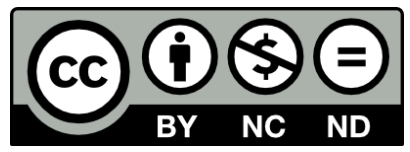

(C) 2020 by the authors. This work is licensed under the Creative Commons AttributionNonCommercial-NoDerivatives 4.0 International License. To view a copy of this license, visit http://creativecommons.org/licenses/by-nc-nd/4.0/ or send a letter to Creative Commons, PO Box 1866, Mountain View, CA 94042, USA. 